\title{
Consent to Publish
}

\section{Title of Book/Volume/Conference: AHFE 2020 International}

\section{Conference Editor(s) name(s): AHFE 2020 Editor}

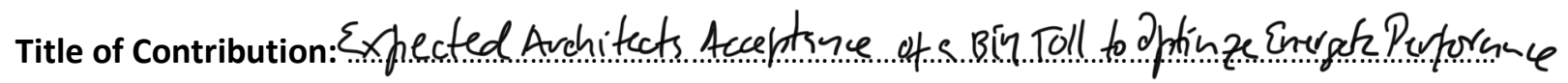

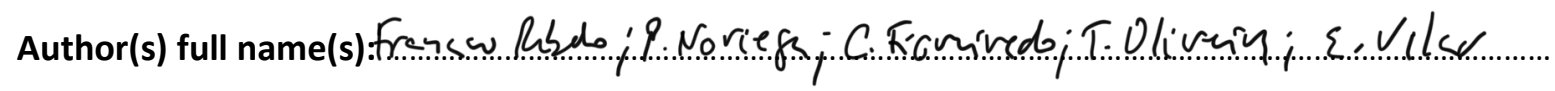

Corresponding Author's name, address, affiliation and e-mail:

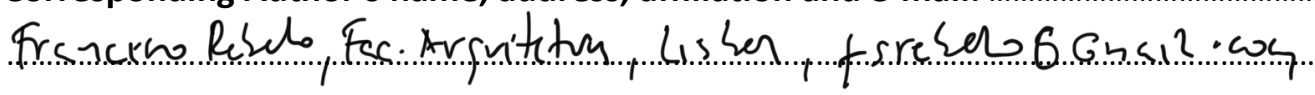

When Author is more than one person the expression "Author" as used in this agreement will apply collectively unless otherwise indicated.

\section{§ 1 Rights Granted}

Author hereby grants and assigns to Springer International Publishing AG, Cham (hereinafter called Springer) the exclusive, sole, permanent, world-wide, transferable, sub-licensable and unlimited right to reproduce, publish, distribute, transmit, make available or otherwise communicate to the public, translate, publicly perform, archive, store, lease or lend and sell the Contribution or parts thereof individually or together with other works in any language, in all revisions and versions (including soft cover, book club and collected editions, anthologies, advance printing, reprints or print to order, microfilm editions, audiograms and videograms), in all forms and media of expression including in electronic form (including offline and online use, push or pull technologies, use in databases and networks for display, print and storing on any and all stationary or portable end-user devices, e.g. text readers, audio, video or interactive devices, and for use in multimedia or interactive versions as well as for the display or transmission of the Contribution or parts thereof in data networks or search engines), in whole, in part or in abridged form, in each case as now known or developed in the future, including the right to grant further time-limited or permanent rights. Springer especially has the right to permit others to use individual illustrations, tables or text quotations and may use the Contribution for advertising purposes. For the purposes of use in electronic forms, Springer may adjust the Contribution to the respective form of use and include links (e.g. frames or inline-links) or otherwise combine it with other works and/or remove links or combinations with other works provided in the Contribution. For the avoidance of doubt, all provisions of this contract apply regardless of whether the Contribution and/or the Work itself constitutes a database under applicable copyright laws or not.

Springer may take, either in its own name or in that of copyright holder, any necessary steps to protect these rights against infringement by third parties. It will have a copyright notice inserted into all editions of the Contribution according to the provisions of the Universal Copyright Convention (UCC) and dutifully take care of all formalities in this connection in the name of the copyright holder.

The parties acknowledge that there may be no basis for claim of copyright in the United States to a Contribution prepared by an officer or employee of the United States government as part of that person's official duties. If the Contribution was performed under a United States government contract, but Author is not a United States government employee, Springer grants the United States government royalty-free permission to reproduce all or part of the Contribution and to authorize others to do so for United States government purposes. If the Contribution was prepared or published by or under the direction or control of Her Majesty (i.e., the constitutional monarch of the Commonwealth realm) or any Crown government department, the copyright in the Contribution shall, subject to any agreement with Author, belong to Her Majesty. If Author is an officer or employee of the United States government or of the Crown, reference will be made to this status on the signature page.

\section{§ 2 Rights retained by Author}

Author retains, in addition to uses permitted by law, the right to communicate the content of the Contribution to other scientists, to share the Contribution with them in manuscript form, to perform or present the Contribution or to use the content for non-commercial internal and educational purposes provided the Springer publication is mentioned as the original source of publication in any printed or electronic materials. 
Author retains the right to republish the Contribution in any collection consisting solely of Author's own works without charge and subject only to notifying Springer in writing prior to such publication of the intent to do so and to ensuring that the publication by Springer is properly credited and that the relevant copyright notice is repeated verbatim.

\section{$\S 3$ Warranties}

Author warrants that the Contribution is original except for such excerpts from copyrighted works (including illustrations, tables, animations and text quotations) as may be included with the permission of the copyright holder thereof, in which case(s) Author is required to obtain written permission to the extent necessary and to indicate the precise sources of the excerpts in the manuscript. Author is also requested to store the signed permission forms and to make them available to Springer if required.

Author warrants that Author is entitled to grant the rights in accordance with Clause 1 "Rights Granted", that Author has not assigned such rights to third parties, that the Contribution has not heretofore been published in whole or in part, that the Contribution contains no libelous statements and does not infringe on any copyright, trademark, patent, statutory right or proprietary right of others, including rights obtained through licenses; and that Author will indemnify Springer against any costs, expenses or damages for which Springer may become liable as a result of any breach of this warranty.

\section{$\S 4$ Delivery of Contribution and Publication}

Author agrees to deliver a manuscript of the Contribution to the responsible Editor on a date to be agreed upon created according to guidelines provided by Springer upon signature.

Springer will undertake the publication and distribution of the Contribution and Work in print and electronic form at its own expense and risk.

\section{$\S 5$ Author's Discount}

Author is entitled to purchase for his/her personal use (if ordered directly from Springer) the Work or other books published by Springer at a discount of $331 / 3 \%$ off the list price for as long as there is a contractual arrangement between Author and Springer and subject to applicable book price regulation.

Resale of such copies or of free copies is not permitted.

\section{$\S 6$ Governing Law and Jurisdiction}

This agreement shall be governed by, and shall be construed in accordance with, the laws of Switzerland. The courts of Zug, Switzerland shall have the exclusive jurisdiction.

Corresponding Author signs for and accepts responsibility for releasing this material on behalf of any and all CoAuthors.

Signature of Corresponding Author:

Date:
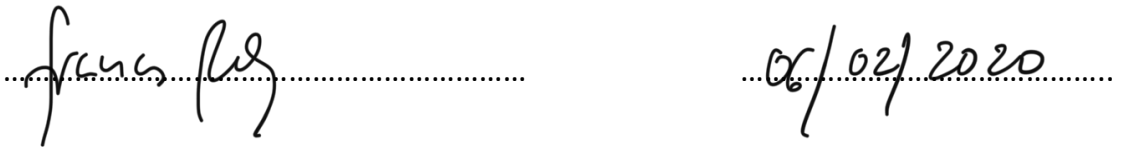

I'm an employee of the US Government and transfer the rights to the extent transferable (Title $17 \S 105$ U.S.C. applies)

I'm an employee of the Crown and copyright on the Contribution belongs to Her Majesty

GPU/PD/PS/RE/DS/Date:

Order Number:

GT-C-CTP-07/2013 